\title{
Improved Open Circuit Voltage in Nano-Porous Silicon based Hydrogen
}

\section{Fuel Cell}

\author{
Himanshu Agarwal and Tejashree M Bhave* \\ Department of Applied Physics, Defence Institute of Advanced Technology, Pune 411025,India \\ *Corresponding Author E-mail : tejashreebhave@diat.ac.in
}

Keywords: Porous Silicon, Hydrogen Fuel Cell, Humidity.

\begin{abstract}
Hydrogen fuel cell generates electrical energy from the electrochemical reaction of hydrogen and oxygen with water vapor as a by-product. Polymer Exchange Membrane Fuel Cell (PEMFC) and Direct Methanol Fuel Cell (DMFC) which are normally utilized for portable applications are not only costly due to platinum electrodes, polymer membrane and supply of hydrogen or methanol as a fuel but also not integrable with silicon fabrication technology. Novel fuel cell based on nano porous silicon (PS) as Metal/nano PS/silicon Schottky type structure is under development and Open Circuit Voltage (Voc) upto $550 \mathrm{mV}$ with $\mathrm{Au}$ as anode catalyst has been reported. Such fuel cell uses nano porous silicon layer as proton exchange membrane. This type of structure is found to show humidity-voltaic effect i.e. generation of voltage in humid ambient. Humidity-stimulated voltage generation is facilitated by the hydrogen component of water present in the atmosphere. In the present work, our main objective was to improve Voc. We achieved Voc upto $1.118 \mathrm{~V}$ by restricting the pore size of nano porous silicon to $4-5 \mathrm{~nm}$ and thickness of the $\mathrm{Cu}$ film to $100 \mathrm{~nm}$. These results suggest that this type of fuel cell could be utilized to develop self powered integrated circuit.
\end{abstract}




\section{Introduction}

Proton Exchange Membrane Fuel Cell (PEMFC) and Direct Methanol Fuel Cell (DMFC) have been utilized for production of clean energy for portable and transportation applications. They utilize a polymer membrane $\left(\mathrm{Nafion}\left({ }^{\circledR}\right)\right.$ as proton conductor sandwiched between the two platinum based catalysts. However, there are various disadvantages of polymer membrane based fuel cells [1]. First is the requirement of generation of pure hydrogen/methanol to supply as fuel. Moreover, using the organic polymer membrane in PEM and DMFC fuel cells and the high-cost platinum catalysts mitigates durability and increases the cost of these fuel cells. Degradation of structural characteristics of polymer membrane material due to diffusion and electro-corrosion processes during electrochemical energy conversion is also a limiting factor. Nano porous silicon is considered suitable as proton conducting membrane [2] for hydrogen fuel cell application due to its unique combination of features, like, retaining crystalline structure with very high surface to volume ratio (upto $1000 \mathrm{~m}^{2} / \mathrm{cm}^{3}$ ) [3], the structure of nano porous silicon is like a sponge in which quantum effects play fundamental role [4]. The pore surfaces of nano porous silicon is covered by Si-H and Si-O which makes it very reactive. These properties of nano porous silicon makes it suitable for gas sensing applications as well [5].

Miniature hydrogen fuel cells utilizing nano porous silicon is under active development [69]. In this paper we are concentrating on Schottky-type fuel cell. This type of fuel cell, based on Metal/PS/silicon-Schottky type structure has been realized and Open Circuit Voltage (Voc) upto 300 $\mathrm{mV}$ with $\mathrm{Cu}$ and $650 \mathrm{mV}$ with $\mathrm{Au}$ as anode catalyst $[10,11]$ have been reported. Such fuel cell uses the porous silicon layer as membrane, $\operatorname{Metal}(\mathrm{Cu}, \mathrm{Au})$ film as electrode-catalyst and this type of fuel cell operates at room temperature in humid atmosphere or under direct supplying of different hydrogen-containing gaseous and liquid fuels. In the present work, our main objective is to improve the Voc. We achieved Voc upto $1.118 \mathrm{~V}$ by restricting the pore size of nano porous silicon to 4-6 nm and also the thickness of the $\mathrm{Cu}$ film to $100 \mathrm{~nm}$. 


\section{Experimental}

The fabrication of fuel cell started with the synthesis of nano porous silicon on silicon substrate. The starting material was p-type silicon wafer with 1-10 ohm $\mathrm{cm}$ resistivity and (100) orientation. The nano porous silicon was formed on silicon wafer by electrochemical etching in 1:1 solution of HF and Ethanol. Graphite was used as cathode and silicon wafer was used as anode. The etching was carried out with current density varying from $5 \mathrm{~mA} / \mathrm{cm}^{2}$ to $100 \mathrm{~mA} / \mathrm{cm}^{2}$. Etching time was kept constant for all samples at 5 minutes. After formation of nano porous silicon, thin copper film was deposited on the nano porous silicon layer by vacuum deposition technique at vacuum of $10^{-5}$ mbar. The thickness of copper film was maintained to $100 \mathrm{~nm}$ during deposition with the help of thickness monitor and shutter in vacuum deposition system.

Finally ohmic contacts were formed on copper side as well as on silicon side to complete the device. Fig. 1 shows the schematic of the $\mathrm{Cu} /$ nano porous silicon/silicon Schottky type fuel cell while the fabricated fuel cell is shown in Fig. 2.

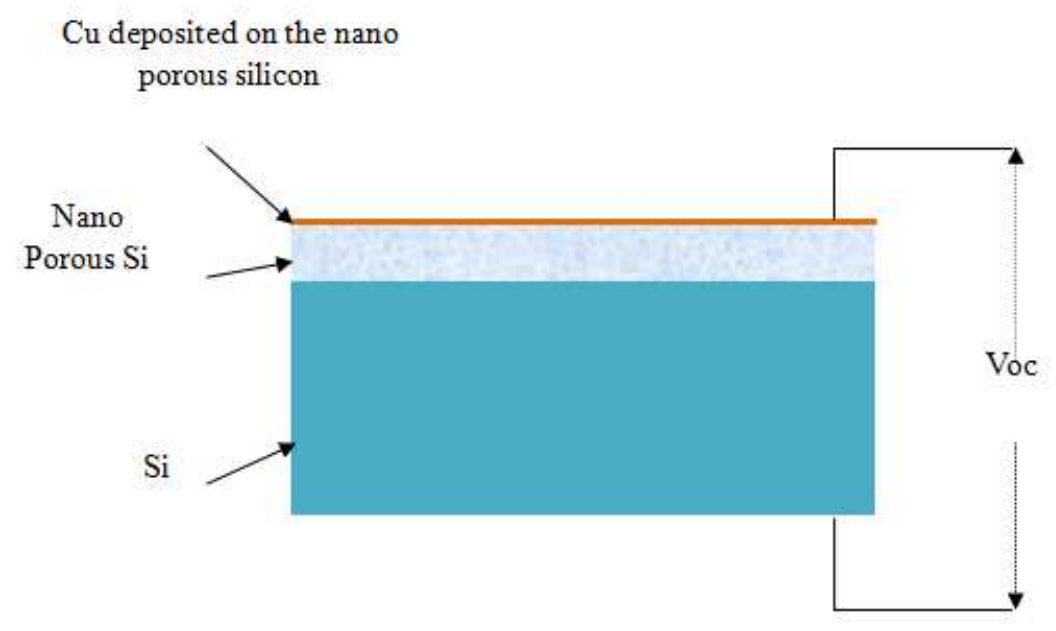

Fig.1. $\mathrm{Cu} /$ nano porous silicon/silicon Schottky type fuel cell. 


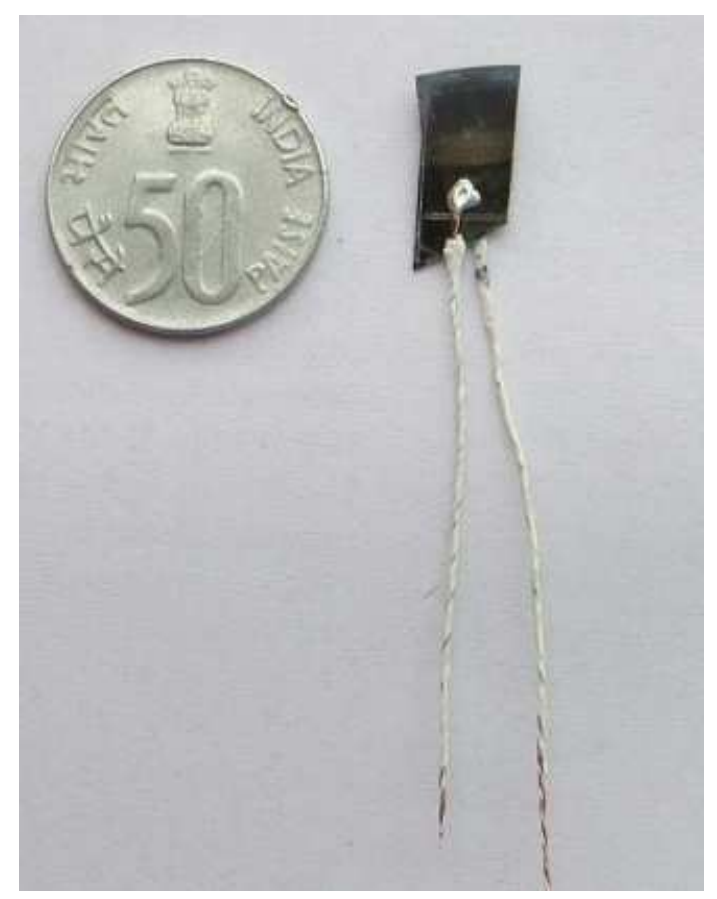

Fig.2. Scale comparison of fabricated Fuel Cell with 50 Paise coin.

Characterisation. After formation of nano porous silicon on silicon substrate, it was characterized with irradiation in UV light, atomic Force Microscopy (AFM), and Fourier Transform Infrared Red Spectroscopy (FTIR). Nano porous silicon when irradiated with UV light gives photoluminescence [12] of orange color as shown in Fig. 3.

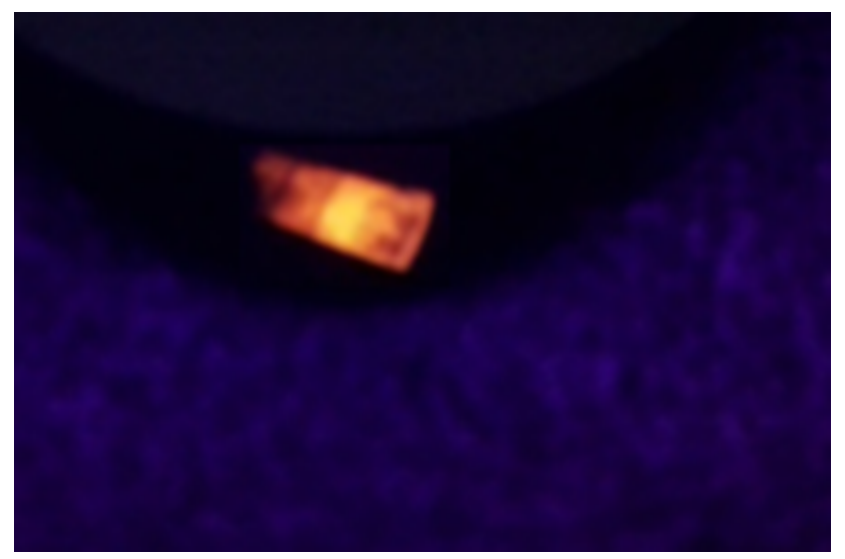

Fig. 3. Orange emission from nano porous silicon in UV light.

The contact mode AFM image of a typical nano porous silicon is shown in Fig. 4. Here, the sample prepared with a current density of $40 \mathrm{~mA} / \mathrm{cm}^{2}$ and etching time of 5 minutes. In the image randomly distributed nano crystallites and voids are clearly visible. 


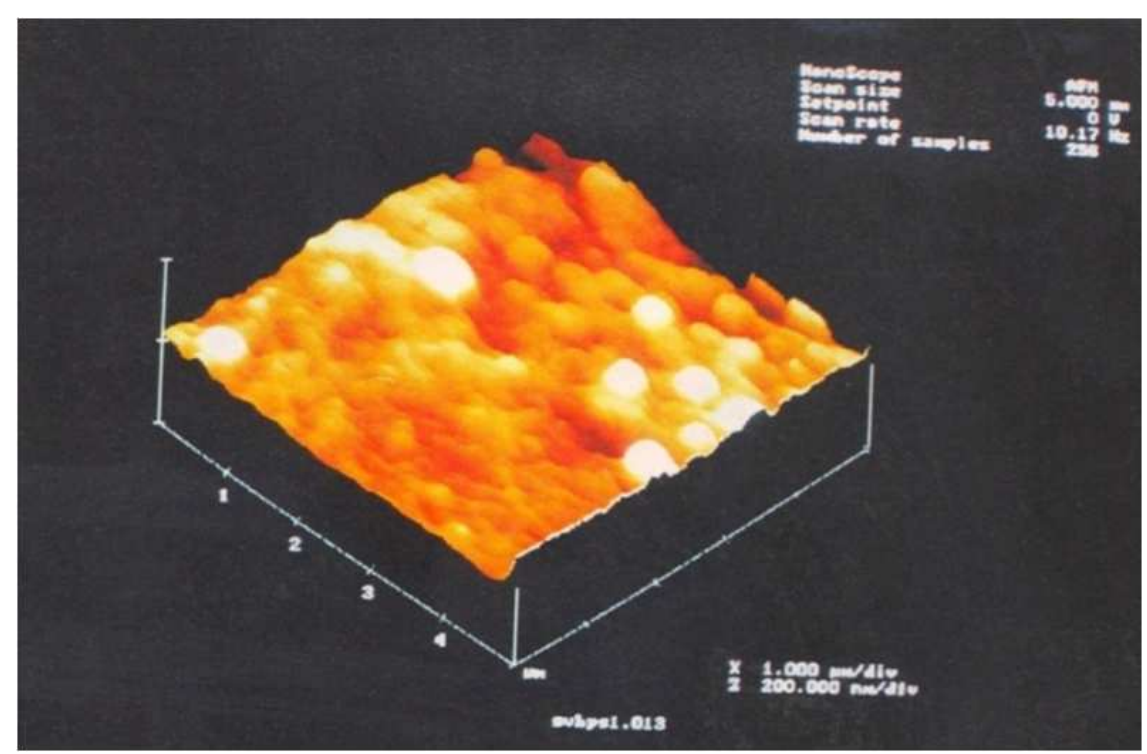

Fig 4. AFM image of prepared nano porous silicon.

Further magnification of the same image showed a single valley providing an average pore size of approximately 4-6 $\mathrm{nm}$ as shown in Fig. 5 .

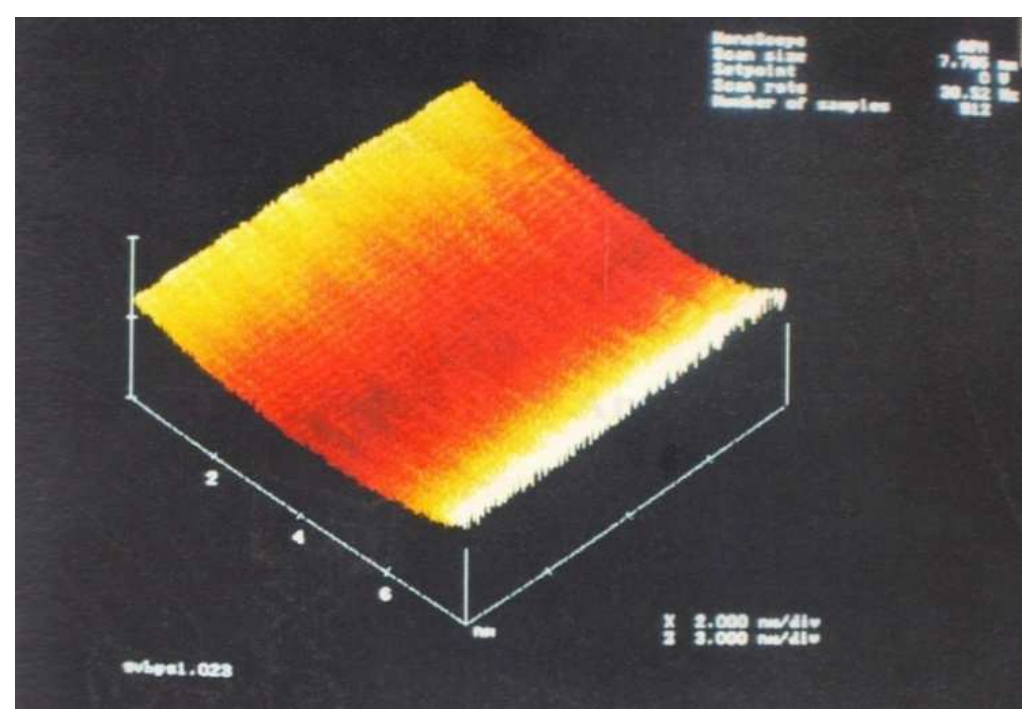

Fig. 5. AFM image of a pore of nano porous silicon.

Fourier transform infrared (FTIR) spectra of the porous silicon were recorded by using FTIR spectrophotometer to get information about the bonds present on the porous silicon. Analysis of the recorded spectrum is tabulated in Table 1 below. 
Table 1: Analysis of obtained spectra of nano porous silicon

\begin{tabular}{|r|c|c|}
\hline S.No & Wave number $\mathrm{cm}^{-1}$ & Analysis \\
\hline 1 & 640 & Si-H bend \\
\hline 2 & 835 & $\mathrm{Si}-\mathrm{H}_{2}$ wagging \\
\hline 3 & 870 & $\mathrm{Si}-\mathrm{H}_{2}$ Scissors \\
\hline 4 & 1050 & $\mathrm{Si}-\mathrm{O}-\mathrm{Si}$ stretch \\
\hline 5 & 2100 & $\mathrm{Si}-\mathrm{H}$ Stretch \\
\hline 6 & 3420 & $\mathrm{O}-\mathrm{H}$ Stretch \\
\hline
\end{tabular}

\section{Results and Discussion}

The open circuit voltage of fabricated fuel cell was measured with Keithley 2182 nanovoltmeter by exposing the fuel cell to various saturated salt solutions whose relative humidity in the air at room temperature is known. The relative humidity of some chemical solutions in the air at room temperature, which we used, is given in Table 2.

Table 2: Salt Solutions and their Relative Humidity in Air [13].

\begin{tabular}{|c|c|}
\hline SALT & \%RH \\
\hline $\mathrm{NaOH}$ & 7.0 \\
\hline $\mathrm{MgCl}_{2}$ & 32.8 \\
\hline $\mathrm{Mg}\left(\mathrm{NO}_{3}\right)_{2}$ & 52.9 \\
\hline $\mathrm{NaCl}$ & 75.3 \\
\hline $\mathrm{CuSO}_{4}$ & 97.2 \\
\hline
\end{tabular}

Performance of Fuel cells prepared with various porous silicon samples (current densities varying from $5 \mathrm{~mA} / \mathrm{cm}^{2}$ to $100 \mathrm{~mA} / \mathrm{cm}^{2}$ ) was tested and Voc were recorded at different relative humidities. We obtained maximum open circuit voltage of 1.118 Volts when fuel cell fabricated with porous silicon sample etched with current density of $40 \mathrm{~mA} / \mathrm{cm}^{2}$ was exposed to saturated solution of $\mathrm{MgCl}_{2}$ i.e \% RH of 32.8. The experimental setup is as shown in Fig. 6. 


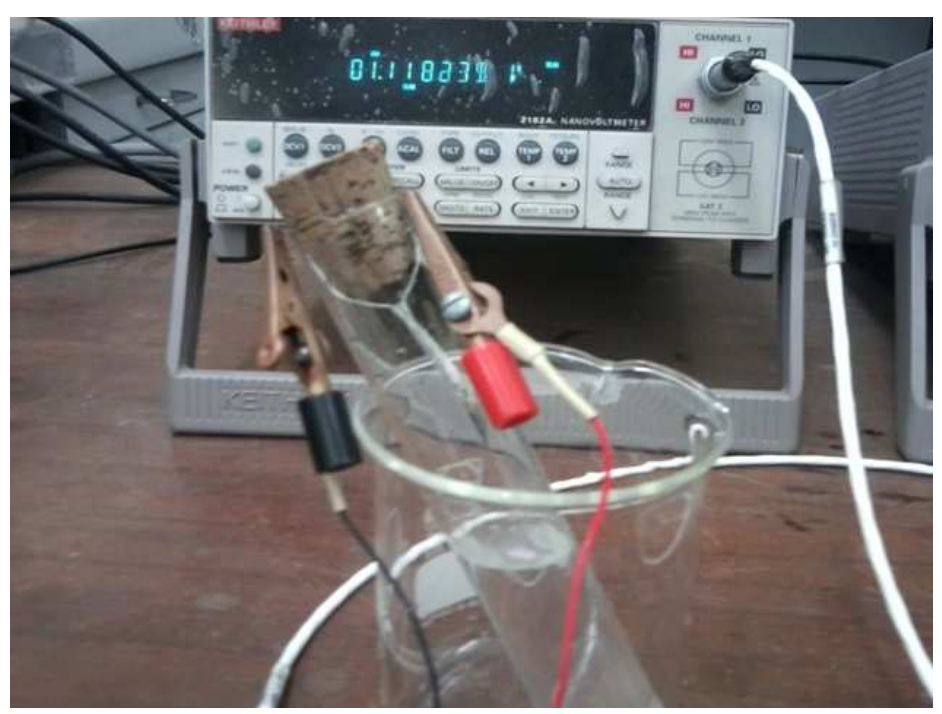

Fig. 6. Experimental setup for Voc measurement.

The graph of open circuit voltage measured in presence of different salt solutions with various relative humidity is presented in Fig. 7.

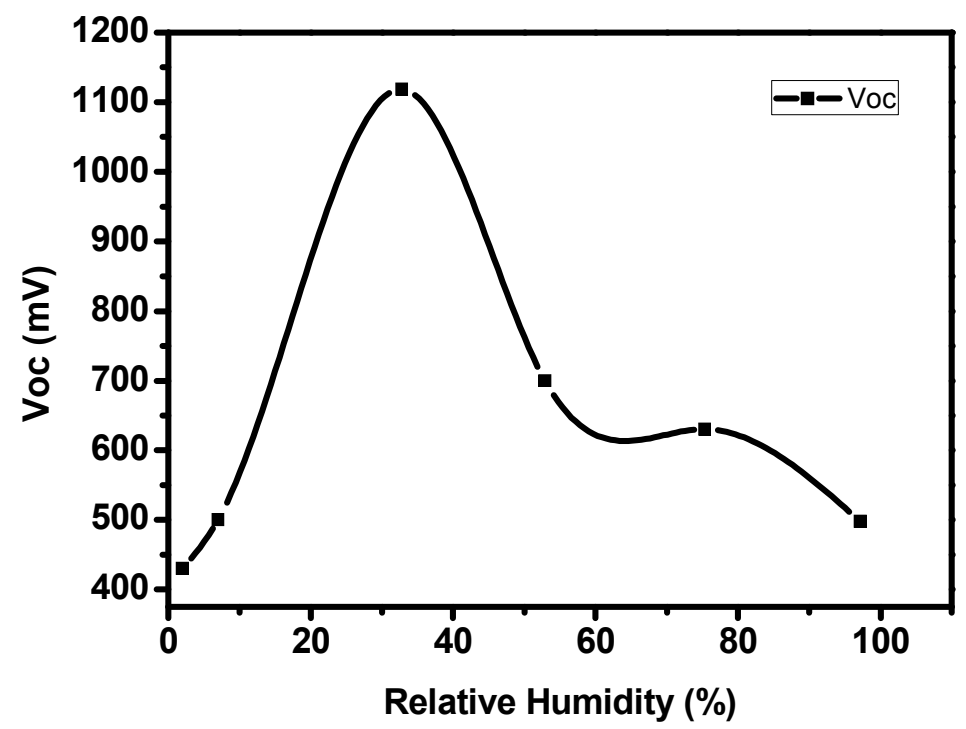

Fig.7. Variation of open circuit voltage with \% relative humidity.

These values of Voc and behavior of Voc with changing relative humidity provides some interesting insights. Initially Voc increases with the increase of relative humidity upto \% RH of 32.8 , thereafter it starts declining. This behavior can be explained by taking into account the two 
competing processes which are taking place in the fuel cell. First one is the splitting of hydrogen into electron and proton and second is the recombination of proton conducted through nano porous silicon membrane, electron traversing from external circuit and oxygen from atmosphere. As the humidity increases the availability of hydrogen also increases at catalytic anode i.e copper film and all the protons which are made available are being conducted towards cathode but when humidity increases beyond $32.8 \%$, the ability of nano porous silicon membrane to conduct proton saturates and flooding of membrane with protons takes place which hinders the proton conduction further, therefore Voc declines. Also at anode the adsorption of hydrogen is saturated beyond \% $\mathrm{RH}$ of 32.8 limiting the number of protons available for conduction in nano porous silicon membrane. The open circuit voltage of $1.118 \mathrm{~V}$ is considered an excellent result as the maximum open circuit voltage which can be obtained from a single hydrogen fuel cell is 1.23 Volts [14]. We have prepared several samples and we found that the combination of controlling the condition during electrochemical etching and controlling the thickness of $\mathrm{Cu}$ deposition are the key to achieve such high Voc. We also observed Voc of approximately 0.9 to 1 volts in ambient which is considered as $45 \% \mathrm{RH}$.

\section{Conclusion}

The generation of much improved Voc of $1.118 \mathrm{~V}$ in miniature hydrogen fuel cell based on nano porous silicon and $\mathrm{Cu}$ anode catalyst has further encouraged the efforts where such fuel cell could be integrated into a silicon chip for realizing the self powered chip. Nonetheless such fuel cell is highly suitable to power miniature electronic devices. Use of $\mathrm{Cu}$ as anode catalyst keeps a check on the overall cost of the fuel cell.

\section{Acknowledgements}

Authors would like to acknowledge DIAT-DRDO Nano Program for research funding. 


\section{References}

[1] K. Kuang, K. Easler, Chapter 8. Constraint of PEM Micro Fuel Cells for Portable Electronics, Fuel Cell Electronics Packaging 2007, 145-163.

[2] N. Gyoko, I. Naohiro, Porous Silicon as a Proton Exchange Membrane for Micro Fuel Cells. Electrochemistry 73 (2005) 939-943.

[3] R. Herino, G. Bomchil, K. Barla, C. Bertrand, J.L. Ginoux, Pore Size Distribution in Porous Silicon, J. Electrochem. Soc. 134 (1987) 1994-2000.

[4] O. Bisi, S. Ossicini, L. Pavesi, Surf. Sci. Rep. 38 (2000) 1-129.

[5] M. Li, M. Hu, D. Jia, S. Ma, W. Yan, $\mathrm{NO}_{2}$-sensing properties based on the nanocomposite of n-WO3-x/n- porous silicon at room temperature, Sens. Actuators, B 186 (2013) 140-147.

[6] T.D. Dzhafarov, S. Aydin Yuksel, Silicon-based Direct Hydrogen Sulphide Fuel Cells, J. Nanosci. Nanotechnol. 11 (2011) 843-848.

[7] K. Chu, M.A. Shanon, R.I. Masel, Porous Silicon Fuel Cell for Micro Power Generation, J. Micromech. Microeng. 17 (2007) S243-S247.

[8] S. Aravamudhan, A. Rahman, S. Bhansali, Porous Silicon Based Orientation Independent Self-priming Micro Direct Ethanol Fuel Cell, Sens. Actuators, A 123-124 (2005) 497-499.

[9] T. Pichonat, B. Gauthier-Manuel, Realization of porous silicon based miniature fuel cells, J. Power Sources 154 (2006) 198-201.

[10] T.D. Dzhafarov, B. Can Omur, C. Oruc, Z.A. Allahverdiev, Hydrogen-sensing Characteristics of Cu-PS-Si Structures, J. Phys. D: Appl. Phys. 35 (2002) 3122-3126. 
[11] T.D. Dzhafarov, S. Aydin Yuksel, Nanoporous silicon-based direct hydrochloric acid fuel cells, Journal of Technology Innovations in Renewable Energy 2 (2013) 115-118.

[12] L.T. Canham, Silicon quantum wire array fabrication by electrochemical and chemical dissolution of wafers, Appl. Phys. Lett. 57 (1990) 1046.

[13] F.J Arregui, Y. Liu, I.R. Matias, R.O. Claus, Optical fiber humidity sensor using a nano Fabry-Perot cavity formed by the ionic self-assembly method, Sens. Actuators, B 59 (1999) 54-59.

[14] J. Larmanie, A. Dicks, Fuel Cell Systems Explained, second ed., John Wiley \& Sons, 2000 